\title{
PVC plasticizer from trimethylolpropane trioleate: synthesis, properties, and application
}

\author{
Laura de Andrade Souza',2* (D), Edson Luiz Francisquetti ${ }^{1}$, Rafael Domingos Dalagnol ${ }^{2}$ (D), \\ Celso Roman Junior ${ }^{3}$ (D), Maria Telma Gomes Schanz ${ }^{4}$ (D), Martin Edmund Maier ${ }^{4}$ (D) \\ and Cesar Liberato Petzhold ${ }^{1}$ (D)
}

\author{
'Instituto de Química, Universidade Federal do Rio Grande do Sul - UFRGS, Porto Alegre, RS, Brasil \\ 2Instituto Federal do Rio Grande do Sul, Campus Farroupilha, Farroupilha, RS, Brasil \\ 3Instituto Federal do Rio Grande do Sul, Campus Caxias do Sul, Caxias do Sul, RS, Brasil \\ ${ }^{4}$ Institut fuer Organische Chemie, Universitaet Tuebingen, Tuebingen, Deutschland \\ *lauradeandradesouza@gmail.com
}

\begin{abstract}
A new oleic acid derivative plasticizer, epoxidized trimethylolpropane trioleate (EPO), has been synthesized and its application in PVC formulations compared with di(2-ethylhexyl) 1,2-cyclohexanoate (DOCH/DEHCH), a commercial phthalate-free plasticizer of petrochemical origin. EPO and their blends with DOCH were added to PVC resin (50 PHR) and the plasticized PVC has been characterized by thermal and mechanical measurements. EPO demonstrated good compatibility with the PVC resin improving the thermal stability and elongation at break. Due to EPO high molar mass, a slight increase in the glass transition temperature and hardness was observed as the content of EPO in the plasticizer blend increased. The results indicate that EPO is a potential plasticizer for PVC when pure and, by replacing $50 \%$ of $\mathrm{DOCH}$, the PVC compound shows similar properties to pure $\mathrm{DOCH}$, but better elongation at break and thermal stability.
\end{abstract}

Keywords: plasticizers, PVC, renewable sources, epoxidized trimethylpropane trioleate, dioctyl cyclohexanoate.

How to cite: Souza, L. A., Francisquetti, E. L., Dalagnol, R. D., Roman Junior, C., Schanz, M. T. G., Maier, M. E., \& Petzhold, C. L. (2021). PVC plasticizer from trimethylolpropane trioleate: synthesis, properties, and application. Polimeros: Ciência e Tecnologia, 31(2), e2021020. https://doi.org/10.1590/0104-1428.20200102.

\section{Introduction}

Poly(vinyl chloride), PVC, is the most widely used thermoplastic in commercial and household applications, such as toys, medical supplies, packaging materials, and others $^{[1]}$. This range of uses is due to the large number of additives that can be incorporated into PVC, originating from rigid to flexible or translucent to opaque products ${ }^{[2]}$. The most used additives in PVC are plasticizers. These compounds can efficiently interact with the polymer due to the existence of the polarized $\mathrm{C}-\mathrm{Cl}$ bond in $\mathrm{PVC}$, which allows the association between the plasticizer and polymer chain during the product's lifetime ${ }^{[3,4]}$.

Many plasticizers used in PVC are derived from petroleum and have phthalates in their structure. Some studies show that these compounds, containing a phthalate fraction, are very toxic and can cause disturbances in the human reproductive system ${ }^{[5-8]}$. The restriction of the use of phthalates, in particular dioctyl phthalate (DOP), as a plasticizer is increasing. In the United States, for example, the Environmental Protection Agency (EPA) has already banned its use in toys that go in children's mouths. Currently, there are many alternative plasticizers to DOP, one of which are secondary alcohol esters of cyclohexanecarboxylic acids, that have been used to prepare flexible PVC compounds with enhanced low temperature flexibility, low toxicity, and improved resistance to outdoor aging ${ }^{[9,10]}$.

Among the commercial non-toxic plasticizers used, di(2-ethylhexyl) 1,2-cyclohexanoate (DOCH) stands out as a highly efficient and phthalate-free primary plasticizer ${ }^{[11-13]}$. Schilling and Kelly ${ }^{[14]}$ found that DOCH is more compatible with PVC in formulations with high contents of plasticizer (100 PHR or more) and, the blend of DOCH with other plasticizers showed a better performance in the range of 60-120 PHR. However, with the increasing restrictions of environmental policies and the imminent depletion of oil, more and more people are opting to replace fossil plasticizers with ones from renewable sources ${ }^{[15]}$.

Vegetable oil-based plasticizers have a high potential to replace petrochemical plasticizers. Among the vegetable plasticizers, epoxidized soybean oil (ESO) stands out, being among the green plasticizers recognized by the Food and Drugs Administration of the United States ${ }^{[16]}$.

Epoxidized soybean oil (ESO) is known as an additive in plasticized PVC since it functions both as a plasticizer and stabilizer. Therefore, Karmalm et al. ${ }^{[17]}$ studied ESO as a primary PVC plasticizer in the formation of plastisols and noticed that after aging the material became stiff and 
opaque, due to the formation of a cross-linking network between ESO and PVC. However, using a suspension PVC resin, it was not observed, concluding that the crosslinking reaction was catalyzed by some component of the PVC plastisol preparation, which was avoided by the addition of stabilizers.

Mao et al ${ }^{[18]}$ studied the ability of ESO, tri(2-ethylhexyl) trimellitate, and their blends as plasticizers for PVC. Both were efficient in plasticizing the polymer and, as expected, plasticizer migration decreased with increasing ESO content. In addition, PVC compounds with higher ESO content showed lower Shore D hardness. Given this, ESO can fully or partially replace the fossil plasticizer.

Epoxidized soybean oil and its methyl esters were tested as plasticizers for PVC by Chaudhary et al. ${ }^{[19]}$. The authors showed that ESO, even having a high molar mass, proved compatible with PVC, plasticizing it efficiently. This study shows that soybean oil and its derivatives can be used as sustainable plasticizers for PVC and meets the requirements for coating wires and cables, among others.

When PVC is used in food packaging, the migration of plasticizers is of increasing concern in terms of toxicity and environmental pollution. Therefore, Coltro et al. ${ }^{[20]}$ studied the migration of several plasticizers from the PVC matrix, including ESO. The authors used olive oil as a simulant for fatty foods and it was proven that ESO showed the highest rate of exudation. Choi et al. ${ }^{[21]}$ also evaluated the migration of ESO simulating fatty food environment using n-heptane. The samples with ESO showed a high exudation rate, around $35 \%$. These results demonstrate that the migration of plasticizers should be constant.

Besides, the search for new plasticizers from ESO or other green sources has been gaining space in recent years $^{[22]}$. Jia et al. ${ }^{[23]}$ synthesized new polyol esters using soybean oil, with glycerol or pentaerythritol, of which two were acetylated and two were additionally epoxidized. The pentaerythritol-derived esters showed the best performance as a PVC plasticizer. Zheng et al. performed the transesterification of methyl esters from waste cooking oil with 2-ethylhexanol ${ }^{[24]}$. These epoxidized esters were tested as plasticizers and the obtained PVC compounds showed improved mechanical and thermal performance, and the migration resistance was reduced. In addition, 2-ethylhexyl epoxidized esters from cooking oil proved to be an effective alternative to dioctyl phthalate, replacing about $40 \%$ of the total plasticizer.

In 2015, Kandula et al. ${ }^{[25]}$ added several functional groups such as epoxy, acetoxy, methoxy, thiirane, and aziridine to soybean oil and evaluated it as a PVC plasticizer. The high viscosity and darker color of the aziridine and thiirane derivatives limited their usefulness, while the physical properties of the other derivatives were acceptable. Methoxy and acetoxy plasticizers of soybean fatty acid esters (methyl and $n$-butyl) showed good PVC compatibility, high efficiency, and gelling properties comparable to the properties of the commercial plasticizer, di-isononyl phthalate.

Owing to environmental concerns and the impending depletion of petroleum, this study developed a new green, phthalate-free plasticizer. This bio plasticizer was synthesized from the epoxidation of a vegetable triester, trimethylolpropane trioleate. The difference to a triglyceride is the absence of hydrogen- $\beta$, which increases the thermal stability in relation to soybean oil derivatives ${ }^{[26]}$. In addition, epoxy groups were added for better compatibility of the bioplasticizer with PVC. This product was tested as a plasticizer, either pure or mixed with DOCH at different concentrations (10 - 50 PHR), and the plasticizer efficiency was investigated through the mechanical and thermal properties.

\section{Materials and Methods}

\subsection{Materials}

PVC was purchased from Braskem (Norvic $\AA$ SP1000) having a volumetric density of $0.52 \pm 0.03 \mathrm{~g} . \mathrm{cm}^{-3}$. Di(2-ethylhexyl)-1,2-cyclohexane dicarboxylate (DOCH) was purchased from Elekeiroz ${ }^{\circledR}($ EKFLEX $\AA$ 8815), with a density of $0.952 \mathrm{~g} . \mathrm{cm}^{-3}$ and a molar mass of $396 \mathrm{~g} . \mathrm{mol}^{-1}$. Trimethylolpropane trioleate (Emulchem OTMP) was purchased from Chemax ${ }^{\circledR}$ with a molar mass of 924 g.mol ${ }^{-1}$. Formic acid and 30\% hydrogen peroxide were purchased from Synth and Nuclear, respectively. External lubricant (Stearic Acid, Gotalube), thermal stabilizer (Ca-Zn, Gotalube GL-4522®), and optical brightener (Hostalux KCD ${ }^{\circledR}$ ) were donated by the Federal Institute of Rio Grande do Sul (IFRS).

\subsection{Epoxidized Trimethylolpropane Trioleate Synthesis (EPO)}

Trimethylolpropane trioleate, OTMP, (30.92 g, $0.10 \mathrm{~mol}$ double bond) was mixed with formic acid $(7.55 \mathrm{~mL}, 0.2 \mathrm{~mol})$ in a round-bottomed tritubulated flask under mechanical stirring followed by the addition of an aqueous solution of $30 \%$ hydrogen peroxide ( $204 \mathrm{~mL}, 2 \mathrm{~mol}$ ) drop by drop for one hour (maintaining a molar ratio of 1:20:2 double bond/hydrogen peroxide/formic acid). This addition was performed at room temperature, and the reaction proceeded for $4 \mathrm{~h}$ at $65^{\circ} \mathrm{C}$. Thereafter $100 \mathrm{~mL}$ of a saturated solution of sodium bisulfite was added and the mixture was stirred for $15 \mathrm{~min}$. The mixture was placed in a separation funnel and washed with $130 \mathrm{~mL}$ diethyl ether. The organic phase was separated and washed with $200 \mathrm{~mL}$ deionized water and $200 \mathrm{~mL}$ brine, and the $\mathrm{pH}$ of the solution should be around 7 . The aqueous solution was discarded, the organic phase dried with anhydrous sodium sulfate, filtered, and concentrated in a rotary evaporator. The isolated product was characterized by ${ }^{1} \mathrm{H}-\mathrm{NMR}$, TGA, GPC, and Brookfield Viscosity. Yield: 55\%

OTMP $={ }^{1} \mathrm{H} \mathrm{NMR}\left(400 \mathrm{MHz}, \mathrm{CDCl}_{3}\right) \delta(\mathrm{ppm}): 5.33(\mathrm{He}$, m, 5.97H), 4.01 (Ha, s, 6H), $2.29(\mathrm{Hb}, \mathrm{t}, 6.10 \mathrm{H}), 1.99(\mathrm{Hd}$ and $\mathrm{Hf}, \mathrm{m}, 11 \mathrm{H}), 1.60(\mathrm{Hc}, \mathrm{m}, 6.28 \mathrm{H}), 1.29\left(\mathrm{CH}_{2}, \mathrm{~m}, 60 \mathrm{H}\right)$, $0.87\left(\mathrm{CH}_{3}, \mathrm{t}, 12 \mathrm{H}\right)$. (Figure $\mathrm{S} 1-$ Supplementary Material).

EPO $={ }^{1} \mathrm{H} \mathrm{NMR}\left(400 \mathrm{MHz}, \mathrm{CDCl}_{3}\right) \delta(\mathrm{ppm}): 3.99(\mathrm{Ha}$, $\mathrm{s}, 6 \mathrm{H}), 2.87(\mathrm{He}, \mathrm{m}, 5.76 \mathrm{H}), 2.28(\mathrm{Hb}, \mathrm{t}, 6.57 \mathrm{H}), 1.59$ (Hd,f, $\mathrm{m}, 6.24 \mathrm{H}), 1.47(\mathrm{Hc}, \mathrm{m}, 20.97 \mathrm{H}), 1.30-1.25\left(\mathrm{CH}_{2}, \mathrm{~m}, 40 \mathrm{H}\right)$, $0.86\left(\mathrm{CH}_{3}, \mathrm{t}, 12 \mathrm{H}\right)$. (Figure S2 - Supplementary Material).

\subsection{PVC compound preparation}

$100 \mathrm{~g}$ of PVC resin (sp1000) was mixed in an intensive mixer, developed by IFRS, with external lubricant (Stearic Acid, 0.5 PHR), thermal stabilizer (Ca-Zn, 3 PHR), and an 
optical brightener (Hostalux, 0.2 PHR) until a temperature of $80{ }^{\circ} \mathrm{C}$ was reached, by shearing with $7200 \mathrm{rpm}$. At this temperature, the plasticizers EPO and/or DOCH (50 PHR) were added, the temperature was increased to $95 \pm 1^{\circ} \mathrm{C}$, and kept stirring for 30 minutes to obtain the dry blend. After this time, the dry blend obtained was calendered in calender with dimensions 149 x 92 x $59 \mathrm{~cm}(\mathrm{H}$ x W x D, MH150C, MH Equipaments $\left.{ }^{\circledR}\right)$ and two horizontal stainless steel rolls (Ø $11 \times 23 \mathrm{~cm}, 25 \mathrm{rpm})$ at $130^{\circ} \mathrm{C}$, forming rectangular films with $22 \times 33 \mathrm{~cm}$ length versus width, and $1 \mathrm{~mm}$ thickness. The films were cut into $11 \times 11 \mathrm{~cm}$ squares, stacked, and pressed at $150{ }^{\circ} \mathrm{C}$ with 8 tons of pressure for $20 \mathrm{~min}$. The pressed squares were cut according to type IV specimen [ASTM D638-02], with $4 \pm 1 \mathrm{~mm}$ thick and $11 \mathrm{~cm}$ in total length, and stored at $25^{\circ} \mathrm{C}$. The samples were labeled 50DOCH, 4010, 2525, 1040, and 50EPO according to Table 1.

\subsection{Characterization of EPO and PVC compounds}

\subsection{1 ${ }^{1} \mathrm{H}$ NMR measurements}

${ }^{1} \mathrm{H}$ NMR spectra were performed in equipment Bruker $400 \mathrm{MHz}$. Samples were dissolved in deuterated chloroform $\left(\mathrm{CDCl}_{3}\right)$, using the chloroform signal at $7.26 \mathrm{ppm}$ for calibration.

\subsubsection{Infrared spectroscopy (FTIR)}

The Infrared spectra (IR) were recorded on a PerkinElmer spectrometer model Frontier in the ATR (attenuated total reflectance) mode, the spectra expressed by the wavenumber ratio $\left(\mathrm{cm}^{-1}\right)$ being the sample analyzed from 6000 to $400 \mathrm{~cm}^{-1}$.

\subsubsection{Gel Permeation Chromatography (GPC)}

Analyzes were performed on Viscotek chromatograph with GPCmax module (VE2001) equipped with detector TDA402 and Shodex columns (806M, 805L, 804L, and 803L). The samples were solubilized in THF and filtered with a Chromafil Xtra PVDF - 45/25 filter with a pore size of $0.45 \mu \mathrm{m}$ before injection. For calibration standard monodisperse polystyrene samples were used.

\subsubsection{Brookfield viscosity}

The viscosity of the solutions was measured at $60^{\circ} \mathrm{C}$ on a DVII + PRO digital viscometer (Brookfield) and the results were expressed as dynamic viscosity $(\mathrm{cP})$.

\subsubsection{Mechanical dynamic analysis}

According to ASTM E1640, the DMA analysis was performed on a Perkin Elmer DMA 8000 equipment at a heating rate of $2{ }^{\circ} \mathrm{C} \cdot \mathrm{min}^{-1}$ using a strain amplitude of $0.010 \mathrm{~mm}$ and a frequency of $1 \mathrm{~Hz}$.

\subsubsection{Hardness Test (Shore A)}

Based on ASTM D2240-15, the test was performed in a standard laboratory atmosphere at a temperature of $23 \pm 2{ }^{\circ} \mathrm{C}$ and relative humidity of $50 \pm 10 \%$ using a Shore A durometer (Woltest ${ }^{\circledR}, 0-100$ Shore $A$ ). The samples were at least $5.0 \mathrm{~mm}$ thick and the analysis was performed at five different positions, $5 \mathrm{~mm}$ apart. The durometer readings were taken after ten seconds of penetration of the durometer tip into the sample.

\subsubsection{Tensile properties}

To determine the tensile properties of PVC samples the universal testing machine (DL2000, EMIC, Brazil) was used, the test was based on ASTM D638-14 at a speed of $50 \mathrm{~mm} . \mathrm{min}^{-1}$ with a load cell of $500 \mathrm{Kgf}$. Five samples were conditioned in a standard laboratory atmosphere. A $25 \mathrm{~mm}$ strain gauge was used, and the samples were $6 \mathrm{~mm}$ wide in the working area and $5 \pm 1 \mathrm{~mm}$ thick.

\subsubsection{Thermogravimetric analyzer}

TGA measurements were performed in a Perkin Elmer TGA4000, based on ASTM E1131-08. The analysis parameters used were a heating ramp from $30^{\circ} \mathrm{C}$ to $900{ }^{\circ} \mathrm{C}$ at a heating rate of $20{ }^{\circ} \mathrm{C} \cdot \mathrm{min}^{-1}$ under an inert atmosphere (nitrogen). The initial mass of the samples was $9.500 \mathrm{mg} \pm 1 \mathrm{mg}$.

\subsubsection{Migration testing}

To evaluate the migration of polymeric matrix plasticizers tests were performed in $n$-heptane according to ASTM D1239-14 ${ }^{[27]}$ and resolution $\mathrm{n}^{\circ} 105$ of ANVISA (National Health Surveillance Agency, Brazil) ${ }^{[28]}$. This test consists of weighing the materials and after submerging seven (7) days in the $n$-heptane, and after this time the samples are weighed again.

\section{Results and Discussion}

\subsection{EPO synthesis}

Since the 1950s, conventional epoxidation, also called Prilezhaev epoxidation, can be used to epoxidize vegetable oils. This conventional epoxidation method uses peracids, with performic, peracetic, and $\mathrm{m}$-chloroperbenzoic being the most common ${ }^{[29]}$. Even though benzoic peracids have high activity in epoxidation, they are characterized by high cost and difficulty in separating the oil and the aqueous phase. Among the other two peracids, performic acid is preferable to peracetic acid, because the latter requires the addition of a strong and corrosive acid as a catalyst (e.g. $\mathrm{HNO}_{3}, \mathrm{HCl}$, $\mathrm{H}_{2} \mathrm{SO}_{4}$ ) and higher temperatures, which can cause hydrolysis of the oxirane ring formed ${ }^{[30,31]}$.

Therefore, when performing reactions on larger scales, it is preferable to use the in situ generated performic acid and for this reason, this method was chosen for the epoxidation of trimethylolpropane trioleate (OTMP) to obtain EPO from the epoxidized product as shown in Figure 1.

\subsection{NMR analysis}

The following signals are observed in the OTMP spectrum (Figure 2A): at $5.3 \mathrm{ppm}$ for oleate fraction of

Table 1. Plasticizer content in each formulation (PHR).

\begin{tabular}{cccccc}
\hline & $50 \mathrm{DOCH}$ & 4010 & 2525 & 1040 & $50 \mathrm{EPO}$ \\
\hline DOCH & 50 & 40 & 25 & 0 & 10 \\
EPO & 0 & 10 & 25 & 40 & 50 \\
\hline
\end{tabular}




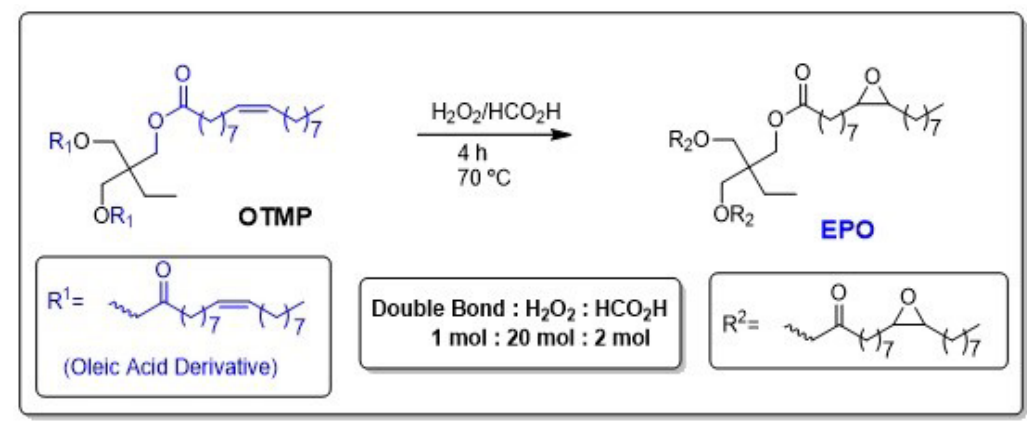

Figure 1. Epoxidation of OTMP to obtain EPO.

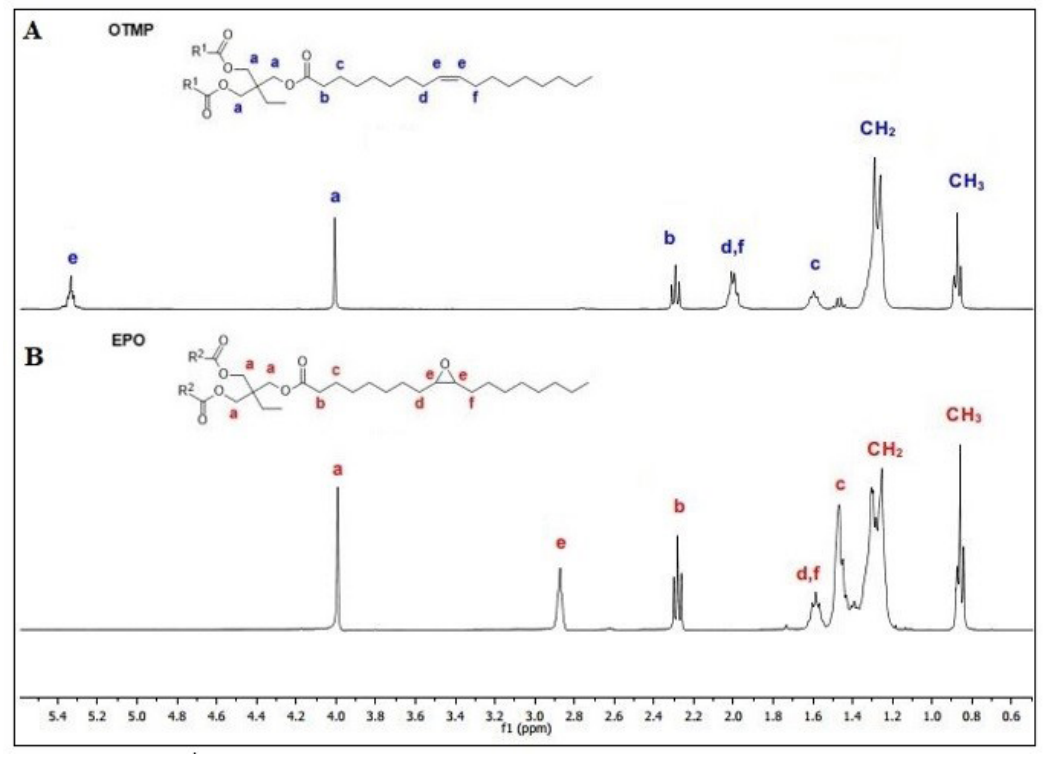

Figure 2. ${ }^{1} \mathrm{H}-\mathrm{NMR}$ spectra of (A) OTMP and (B) EPO (400 MHz, $\left.\mathrm{CDCl}_{3}\right)^{[1]}$.

vinyl hydrogens; at $4.0 \mathrm{ppm}$, the methylene hydrogens $\mathrm{CH}_{2}-\mathrm{O}$; at $2.3 \mathrm{ppm}$, the methylene hydrogens $\mathrm{CH}_{2}-\mathrm{CO}$; at $2.0 \mathrm{ppm}$, allylic methylene hydrogens $\mathrm{CH}_{2}-\mathrm{CH}=\mathrm{CH}$, at $1.6 \mathrm{ppm}$, the methylene hydrogens $\mathrm{CH}_{2}-\mathrm{CH}_{2}-\mathrm{CO}$, at $1.3 \mathrm{ppm}$, the aliphatic methylene hydrogens and $0.9 \mathrm{ppm}$ methyl hydrogens $-\mathrm{CH}_{3}$. The lower intensity signals at 3.5 and $2.8 \mathrm{ppm}$ refer to hydrogens derived from linoleate present in the starting reagent ${ }^{[32]}$.

The EPO NMR spectrum (Figure 2B) was confirmed the complete consumption of the double bonds (signal disappearance at 5.0 and $2.0 \mathrm{ppm}$ ) and the appearance of the signal at $2.9 \mathrm{ppm}$, corresponding to the hydrogens of the oxirane ring and at $1.5 \mathrm{ppm}$ of the methylene hydrogens adjacent to the oxirane.

The product was obtained with a conversion of $100 \%$ of the double bonds and approximately $81 \%$ epoxy selectivity (calculated by Equation 1 using the integration obtained through ${ }^{1} \mathrm{H}$ NMR spectrum), giving a functionality of 2.3 epoxy groups.mol ${ }^{-1}$. As it is known from literature ${ }^{[33]}$ excess formic acid and long reaction times can lead to opening reactions of the epoxy group resulting in $\mathrm{OH} /$ formiate groups.

$$
\text { Selectivity }=\frac{\text { Hepoxide }}{H \text { doublebond }} * 100
$$

\subsection{FTIR analysis}

The FTIR spectra of OTMP and EPO are shown in Figure 3. In the OTMP spectrum was observed the double bond signal at $3014 \mathrm{~cm}^{-1}(=\mathrm{C}-\mathrm{H}$ stretch due to cis unsaturated fatty acid), which disappears in EPO IR-spectrum and a new absorption band at $810 \mathrm{~cm}^{-1}$ attributed to the $\mathrm{C}-\mathrm{O}-\mathrm{C}$ asymmetric bending of the epoxy group is observed ${ }^{[34]}$.

\subsection{GPC and brookfield analysis}

Table 2 shows the number average molar mass and Brookfield viscosity of the OTMP, EPO, and the commercial PVC plasticizer, DOCH. The number average molar mass was determined by GPC using a calibration curve with standard monodisperse polystyrene samples and THF as eluent. Therefore, the obtained $\mathrm{Mn}$ is a relative value and depends on the hydrodynamic volume of the molecule in 
solution. The compounds based on trimethylolpropane esters showed higher viscosity and higher molar mass than DOCH. Although EPO and OTMP have similar molar masses, EPO showed a higher viscosity than OTMP, probably due to the presence of stronger intermolecular interactions due to the presence of epoxy groups. However, etherification and esterification of the epoxide groups of EPO generating compounds with higher molar mass cannot be ruled out as observed in GPC curves of the plasticizers in Figure S3 (Supplementary Material).

\subsection{TGA analysis}

TGA/DTG curves of the plasticizers performed under an inert atmosphere are presented in Figure 4, and initial decomposition $\mathrm{T}_{\text {onset }}$, and maximum degradation rate temperature $\left(\mathrm{T}_{\max }\right)$ are summarized in Table 3 . The compounds derived from vegetable oil (OTMP and EPO) showed higher thermal stability than $\mathrm{DOCH}$, which presents a degradation process with $\mathrm{T}_{\text {onset }}$ at $204^{\circ} \mathrm{C}$ and $\mathrm{T}_{\text {max }}$ at $315^{\circ} \mathrm{C}$. While OTMP presented only one process of weight loss with $\mathrm{T}_{\text {onset }}$ at $342{ }^{\circ} \mathrm{C}$ and $\mathrm{T}_{\max }$ at $441^{\circ} \mathrm{C}$, EPO degraded in two processes: from 200 to $400{ }^{\circ} \mathrm{C}$, due to the elimination of formiate groups attached to the opened oxirane rings corresponding to $11 \%$ weight loss and from 400 to $500{ }^{\circ} \mathrm{C}$, relative to the main carbon chains degradation. As expected, the epoxidation of double bonds increases the thermal stability of the compounds ${ }^{[35,36]}$. None of the three compounds presented residue.

\subsection{Characterization of PVC compounds}

Characterization was performed on the specimens produced according to the formulation in Table 1. It was not possible to obtain a specimen as pure PVC, because degradation occurs during calendering, and the OTMP cannot plasticize PVC.

\subsubsection{DSC analysis}

An essential parameter of the plasticizer efficiency is the reduction of the glass transition temperature (Tg) compared to pure PVC. The Tg of the PVC resin used is $86^{\circ} \mathrm{C}$ (determined by DSC in Figure S4 - Supplementary Material). The DSC heating curve of pure EPO showed a melting peak around $-10{ }^{\circ} \mathrm{C}$ (Figure 5) which was not

Table 2. Number average molar mass and Brookfield viscosity of PVC plasticizers.

\begin{tabular}{ccc}
\hline & Mn $\left(\mathrm{g} \cdot \mathrm{mol}^{-1}\right)$ & Viscosity $(\mathrm{cP})$ \\
\hline DOCH & 373 & 9.49 \\
OTMP & 1325 & 22.35 \\
EPO & 1317 & 52.85 \\
\hline
\end{tabular}

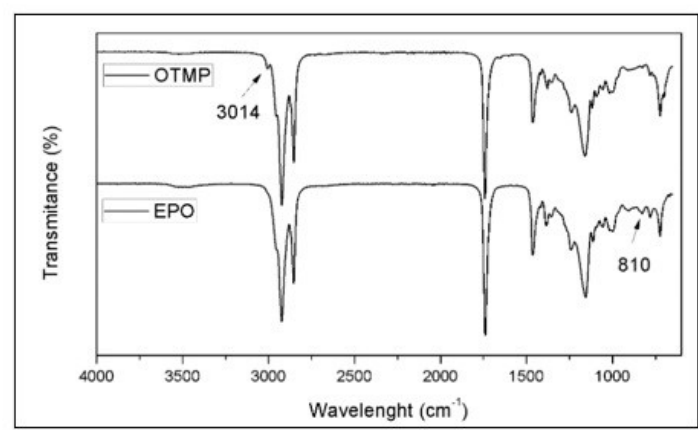

Figure 3. FTIR spectra of OTMP and EPO.

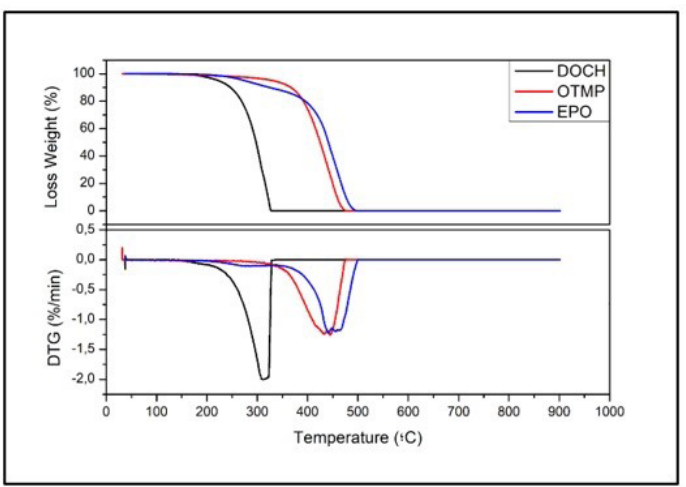

Figure 4. TGA and DTG curves of the plasticizers DOCH, OTMP, and $\operatorname{EPO}\left(\mathrm{N}_{2}, 20^{\circ} \mathrm{C} \cdot \mathrm{min}^{-1}\right)$.

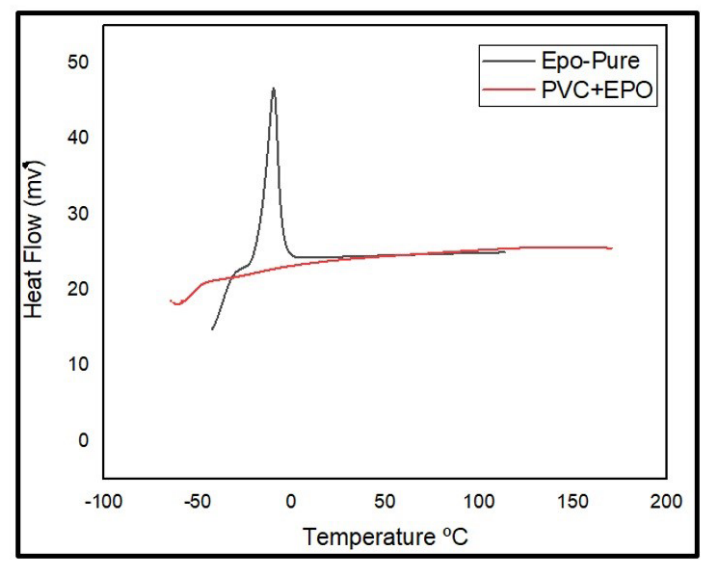

Figure 5. DSC heating curves of EPO and PVC $50 \mathrm{EPO}\left(20^{\circ} \mathrm{C} / \mathrm{min}\right.$, $\mathrm{N}_{2}$ atmosphere).

Table 3. Thermal degradation temperatures of DOCH, OTMP, and EPO.

\begin{tabular}{ccccc}
\hline & & DOCH & OTMP & EPO \\
\hline \multirow{3}{*}{ First Process } & $\mathbf{T}_{\text {onset }}\left({ }^{\circ} \mathrm{C}\right)$ & 204 & 342 & 219 \\
& $\mathbf{T}_{\max }\left({ }^{\circ} \mathrm{C}\right)$ & 315 & 441 & 279 \\
& $\mathbf{L o s s}$ Weight $(\mathbf{\%})$ & 100 & 100 & 11 \\
\multirow{3}{*}{ Second Process } & $\mathbf{T}_{\text {onset }}\left({ }^{\circ} \mathrm{C}\right)$ & -- & -- & 364 \\
& $\mathbf{T}_{\max }\left({ }^{\circ} \mathrm{C}\right)$ & -- & -- & 453 \\
& Loss Weight (\%) & -- & & 89 \\
\hline
\end{tabular}


observed in the plasticized PVC, indicating compatibility between the PVC and the plasticizer. As observed in Table 4, the addition of EPO to PVC decreased the glass transition temperature by about $30^{\circ} \mathrm{C}$ compared to resin, as there is a weakening of intermolecular interactions and an increase in the free volume between the PVC chains resulting in higher overall mobility of the main chain ${ }^{[37-40]}$.

The polar ester and epoxy groups of the plasticizers interact with the polar part of the PVC polymer chain, spacing out the PVC molecules reducing their friction, and increasing the compatibility ${ }^{[1]}$. Furthermore, the long non-polar alkyl chain can increase the free volume between polymer molecules, resulting in a reduction of $\mathrm{Tg}^{[41]}$.

\subsubsection{Mechanical properties}

The compatibility and plasticized effect of EPO in PVC were investigated by DMA measurements. The Tg of the PVC compounds was obtained by the maximum peak of the $\tan \delta$. Figure 6 shows $\tan \delta$ versus temperature curves of plasticized PVC with DOCH and EPO mixtures. All compounds presented only one symmetrical $\tan \delta$ peak, indicating that the materials are uniform, in other words, the plasticizers are compatible with $\mathrm{PVC}^{[6,42]}$.

Therefore, the sample 50DOCH presents a lower glass temperature than EPO plasticized samples, since EPO has a molar mass three times higher than DOCH. Similar results were observed by Omrani et al. ${ }^{[43]}$ using a bio-based plasticizer from oleic acid.

However, in the work of Ma et al. ${ }^{[44]}$, the addition of a compound with a high molar mass causes an increase in the free volume of the molecule and, consequently, a decrease in the glass transition temperature. This effect was related to the dendritic structure of the molecule, which promotes the separation of PVC molecules. Tan et al. ${ }^{[4]}$ also observed that the incorporation of flexible oxyethyl units in the plasticizer can efficiently reduce the $\mathrm{Tg}$ of the plasticized $\mathrm{PVC}$, although the higher molar mass.

The storage modulus of the PVC compounds (Figure 7) increases as the amount of EPO increases, indicating greater resistance to deformation. These data corroborate with the high Tg and Shore A hardness values (Table 4), because the higher the energy storage, the lower the free volume, which leads to increased stiffness of the PVC compound. Similar results were reported by Feng et al. ${ }^{[45]}$ when using cooking oil modified with an alkyl diacid as a bio plasticizer.

The efficiency of the plasticizer can also be described by hardness measurements because it is associated with the free volume in the PVC matrix ${ }^{[46]}$. The lower the hardness of the material, the higher the mobility of the PVC chains, consequently, the better is the plasticization efficiency. The addition of EPO to the PVC matrix has slightly increased the hardness of the material regarding the formulation with the commercial DOCH (Table 4), which should be associated with its higher molar mass in comparison with DOCH.
Omrani et al. also obtained similar Shore A hardness for PVC plasticized with a bio-based plasticizer synthesized from the oleic acid and thioglycolic acid ${ }^{[42]}$.

Mehta et al. ${ }^{[47]}$ prepared PVC plasticized with a blend containing 26 PHR of DOP and 26 PHR of an epoxy acylated ricinoleic acid binary alcohol ether ester and obtained a compound with a hardness of 95 Shore A. This value is much higher when compared with the hardness of 50EPO (89 Shore A), using 50 PHR of vegetable triester.

Table 5 shows the mechanical properties of PVC compounds. The addition of EPO increases the elastic modulus and the elongation at break of the material; however, no significant variation of tensile strength was observed indicating that $\mathrm{EPO}$ is a potential plasticizer to substitute the petrochemical DOCH.

The elongation at break reached the highest value ( $24 \%$ higher than 50DOCH) when equal weight proportions of $\mathrm{DOCH}$ and EPO are presented (2525). Similar results were

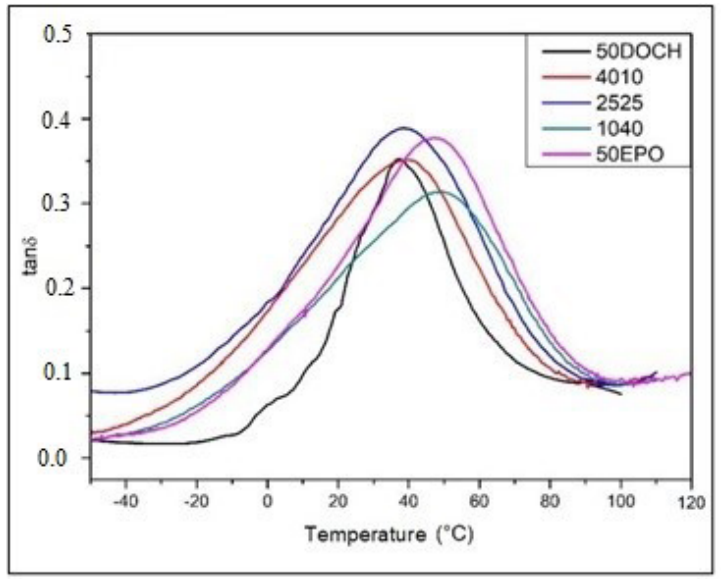

Figure 6. Tan $\delta$ versus temperature for PVC compounds.

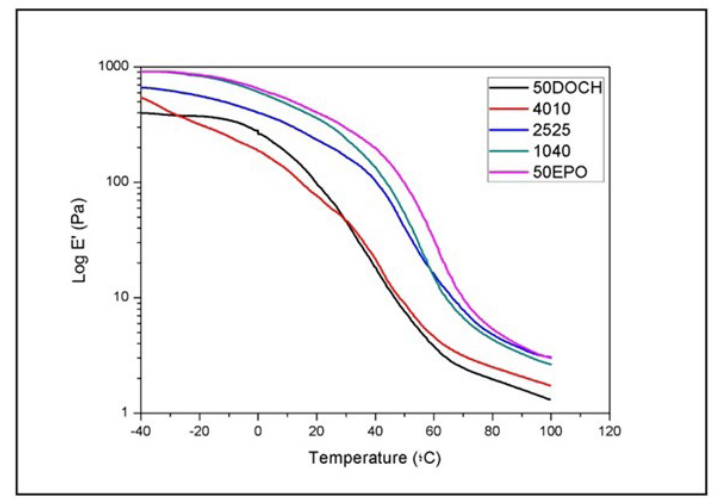

Figure 7. Storage modulus versus temperature of PVC compounds.

Table 4. Properties of PVC compounds.

\begin{tabular}{cccccc}
\hline & $50 \mathrm{DOCH}$ & 4010 & 2525 & 1040 & $50 \mathrm{EPO}$ \\
\hline $\operatorname{Tg}\left({ }^{\circ} \mathrm{C}\right)$ & 37 & 38 & 40 & 48 & 46 \\
Hardness (Shore A) & 82 & 83 & 86 & 88 & 89 \\
\hline
\end{tabular}


Table 5. Mechanical properties of PVC compounds.

\begin{tabular}{ccccc}
\hline Sample & $\begin{array}{c}\text { Tensile strength at break } \\
(\mathrm{MPa})\end{array}$ & Young's Modulus (MPa) & Tensile strength (MPa) & Elongation at break (\%) \\
\hline 50DOCH & $14.4 \pm 0.8$ & $31.5 \pm 4.8$ & $2.3 \pm 0.1$ & $215 \pm 22$ \\
4010 & $14.1 \pm 1.0$ & $32.3 \pm 2.9$ & $2.5 \pm 0.2$ & $221 \pm 74$ \\
2525 & $14.8 \pm 0.2$ & $34.7 \pm 2.4$ & $2.4 \pm 0.1$ & $268 \pm 20$ \\
1040 & $14.3 \pm 0.1$ & $69.7 \pm 0.7$ & $2.4 \pm 0.1$ & $231 \pm 04$ \\
5 EPO & $14.2 \pm 0.6$ & $64.2 \pm 2.5$ & $2.6 \pm 0.1$ & $227 \pm 26$ \\
\hline
\end{tabular}

Table 6. TGA data of PVC resin and compounds.

\begin{tabular}{cccccc}
\hline & $\mathrm{T}_{\text {onset }}\left({ }^{\circ} \mathrm{C}\right)$ & $\mathrm{T}_{50}\left({ }^{\circ} \mathrm{C}\right)$ & $\mathrm{T}_{\mathrm{M} 1}\left({ }^{\circ} \mathrm{C}\right)$ & $\mathrm{T}_{\mathrm{M} 2}\left({ }^{\circ} \mathrm{C}\right)$ & Residue $(\%)$ \\
\hline PVC-Resin & 238 & 346 & 318 & 477 & 4.9 \\
50 DOCH & 230 & 325 & 319 & 379 & 3.9 \\
4010 & 257 & 333 & 312 & 481 & 5.6 \\
2525 & 264 & 347 & 329 & 483 & 6.1 \\
1040 & 276 & 358 & 340 & 477 & 5.8 \\
50 EPO & 278 & 379 & 341 & 479 & 5.4 \\
\hline
\end{tabular}

observed for the plasticizing effect of epoxy soybean oil compared with dioctyl phthalate petrochemical plasticizer ${ }^{[48]}$. Feng et al. also obtained a much higher elongation at break using a natural origin plasticizer ${ }^{[45]}$.

\subsubsection{TGA analysis}

The thermal stability of the PVC compounds was investigated by thermogravimetric analysis (TGA) as showed in Figure 8. The thermal data as initial decomposition and $50 \%$ loss weight temperatures $\left(\mathrm{T}_{\text {onset }}\right.$ and $\left.\mathrm{T}_{50}\right)$ and, the maximum degradation rate temperature corresponding to each process $\left(\mathrm{T}_{\mathrm{M} 1}\right.$ and $\left.\mathrm{T}_{\mathrm{M} 2}\right)$ were summarized in Table 6 .

All PVC compounds showed the characteristic two-loss weight processes. The first one corresponds to the PVC dehydrochlorination and the second to the formation of aromatic and allyl compounds followed by degradation of hydrocarbons chains. After the hydrogen chloride loss and breakage of double bonds, cross-linking occurs between polymer chains originating carbon black, which explains the residue of 4 to $6 \%$ regarding the initial weight of the PVC resin ${ }^{[49,50]}$

While for the formulation with commercial plasticizer DOCH $(50 \mathrm{DOCH})$ the thermal stability decreased, all specimens formulated with EPO improved the thermal stability. The initial degradation temperature, $\mathrm{T}_{50}$, and $\mathrm{T}_{\mathrm{M} 1}$ increase as the content of EPO increases. Comparing pure PVC resin with 50EPO, an increase of $40{ }^{\circ} \mathrm{C}$ in the $\mathrm{T}_{\text {onset }}$ was observed, better than the results obtained for plasticizers based on epoxidized soybean oil ${ }^{[45,48]}$. Only $\mathrm{T}_{\mathrm{M} 2}$ remains very close to $\mathrm{PVC}$ resin confirming that the plasticizer acts directly on the loss of hydrochloric acid from PVC. As described in the literature the epoxy groups can absorb hydrogen chloride degraded by light and heat, preventing the continuous decomposition of PVC and prolonging its lifetime ${ }^{[1]}$.

\subsubsection{Migration test}

The migration stability of the EPO plasticizer in PVC blends was preliminarily investigated by leaching test using $n$-heptane, which is a good solvent for the bio plasticizers and

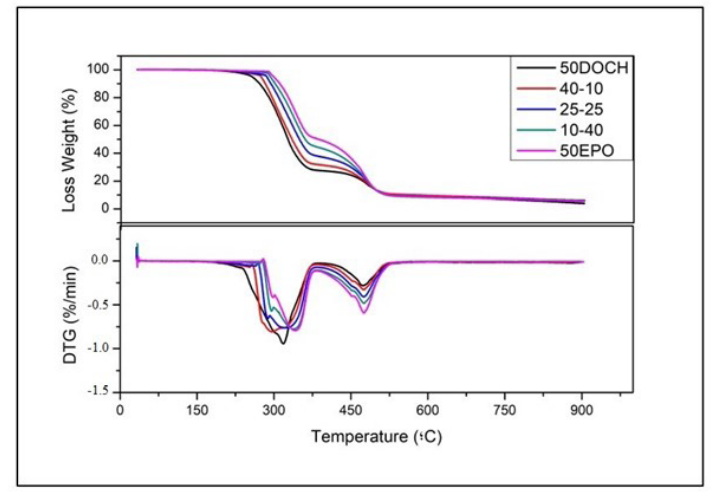

Figure 8. TGA and DTG curves of PVC compounds $\left(\mathrm{N}_{2}, 20^{\circ} \mathrm{C} \cdot \mathrm{min}^{-1}\right)$.

a fatty food simulant ${ }^{[27,28]}$. The plasticizers presented lower leaching resistance in $n$-heptane (weight loss higher than $10 \%$ ) since they are organic compounds. Unsurprisingly the extraction of a high molar mass plasticizer EPO was lower than the low molar mass plasticizer DOCH, improving the resistance to exudation ${ }^{[51]}$. The weight loss results (average value among five samples) were $19 \%$ for $50 \mathrm{DOCH}, 13 \%$ for $50 \mathrm{EPO}$, and $10 \%$ for 2525 .

\section{Conclusions}

Epoxidized trimethylolpropane trioleate (EPO), an acid oleic derivate, was easily synthesized and used as PVC environment-friendly plasticizer in substitution to commercial di(2-ethylhexyl) 1,2-cyclohexanoate (DOCH). Blends of DOCH/EPO (50 PHR) were added to PVC and their properties investigated. The presence of the epoxidized renewable source compound had a direct influence on the degradation temperature of $\mathrm{PVC}$, making the polymer matrix more stable for all formulations compared to the commercial plasticizer DOCH.

EPO demonstrated good compatibility with PVC, which is evidenced by the presence of only one $\tan \delta$ peak 
in the DMA analysis and the improvement of mechanical characteristics of PVC compounds. Thus, the tensile strength, Young modulus, and elongation at break increase achieving the best effect for a mixture containing equal amounts of $\mathrm{DOCH} / \mathrm{EPO}$.

Therefore, it can be stated that EPO is a potential bio plasticizer that can replace $\mathrm{DOCH}$, a plasticizer of fossil origin, and by replacing DOCH with 50\% EPO significantly improved the mechanical and thermal properties of the PVC compound.

\section{Acknowledgments}

The authors acknowledge CAPES and DAAD for the financial support in the partnership program PROBRAL (project nr. 88887.144057/2017-00). L. Souza thanks CAPES and Federal Institute of Rio Grande do Sul (IFRSCampus Farroupilha).

\section{References}

1. Hosney, H., Nadiem, B., Ashour, I., Mustafa, I., \& El-Shibiny, A. (2018). Epoxidized vegetable oil and bio-based materials as PVC plasticizer. Journal of Applied Polymer Science, 135(20), 46270. http://dx.doi.org/10.1002/app.46270.

2. Shah, B. L., \& Shertukde, V. V. (2003). Effect of plasticizers on mechanical, electrical, permanence, and thermal properties of poly (vinyl chloride). Journal of Applied Polymer Science, 90(12), 3278-3284. http://dx.doi.org/10.1002/app.13049.

3. Unar, I. N., Soomro, S. A., \& Aziz, S. (2010). Effect of various additives on the physical properties of polyvinylchloride resin. Pakistan Journal of Analytical \& Environmental Chemistry, 11(2), 44-50. Retrieved in 2020, December 17, from http:// pjaec.pk/index.php/pjaec/article/view/107/117

4. Daniels, P. H. (2009). A brief overview of theories of pvc plasticization and methods used to evaluate pvc-plasticizer interaction. Journal of Vinyl \& Additive Technology, 15(4), 219-223. http://dx.doi.org/10.1002/vnl.20211.

5. Latini, G., De Felice, C., \& Verrotti, A. (2004). Plasticizers, infant nutrition and reproductive health. Reproductive Toxicology (Elmsford, N.Y.), 19(1), 27-33. http://dx.doi.org/10.1016/j. reprotox.2004.05.011. PMid:15336709.

6. Tan, J., Zhang, S., Lu, T., Li, R., Zhong, T., \& Zhu, X. (2019). Design and synthesis of ethoxylated esters derived from waste frying oil as anti-ultraviolet and efficient primary plasticizers for poly (vinyl chloride). Journal of Cleaner Production, 229, 1274-1282. http://dx.doi.org/10.1016/j.jclepro.2019.04.395.

7. Radke, E. G., Galizia, A., Thayer, K. A., \& Cooper, G. S. (2019). Phthalate exposure and metabolic effects: a systematic review of the human epidemiological evidence. Environment International, 132, 104768. http://dx.doi.org/10.1016/j. envint.2019.04.040. PMid:31196577.

8. Tickner, J. A., Schettler, T., Guidotti, T., McCally, M., \& Rossi, M. (2001). Health risks posed by use of Di-2-ethylhexyl phthalate (DEHP) in PVC medical devices: a critical review. American Journal of Industrial Medicine, 39(1), 100-111. http://dx.doi.org/10.1002/1097-0274(200101)39:1<100::AIDAJIM10>3.0.CO;2-Q. PMid:11148020.

9. Bui, T. T., Giovanoulis, G., Cousins, A. P., Magnér, J., Cousins, I. T., \& de Wit, C.A. (2016). Human exposure, hazard and risk of alternative plasticizers to phthalate esters. The Science of the Total Environment, 541, 451-467. http://dx.doi.org/10.1016/j. scitotenv.2015.09.036. PMid:26410720.

10. Colle, K. S., Stanat, J. E. R., Reinoso, J. J., \& Godwin, S. (2010). US Patent No. 20100305250A1. USA: USPTO. Retrieved in
2020, December 17, from https://patents.google.com/patent/ US20100305250A1/en

11. Ou, Y., Ding, X., \& Zhang, L. (2014). Synthesis and application of an alternative plasticizer Di (2-Ethylhexyl)-1, 2-cyclohexane dicarboxylate. Journal of Applied Polymer Science, 131(2), n/a. http://dx.doi.org/10.1002/app.39763.

12. Hou, L., Fan, C., Liu, C., Qu, Q., Wang, C., \& Shi, Y. (2018). Evaluation of repeated exposure systemic toxicity test of $\mathrm{PVC}$ with new plasticizer on rats via dual parenteral routes. Regenerative Biomaterials, 5(1), 9-14. http://dx.doi.org/10.1093/ $\mathrm{rb} / \mathrm{rbx} 020$. PMid:29423263.

13. Hab, S. A., Talpur, F. N., Baig, J. A., Afridi, H. I., Surhio, M. A., \& Talpur, M. K. (2018). Leaching and exposure of phthalates from medical devices; health impacts and regulations. Environmental Contaminants Reviews, 1(2), 13-21. http:// dx.doi.org/10.26480/ecr.02.2018.13.21.

14. Schilling, C. L. 3rd, \& Kelly, K. K. (2018). U.S. Patent US: 2018/0105673 A1. Kingsport: U.S. Patent and Trademark Office.

15. Mizik, T., \& Gyarmati, G. (2021). Economic and sustainability of biodiesel production: a systematic literature review. Cleanroom Technology, 3(1), 19-36. http://dx.doi.org/10.3390/ cleantechnol3010002.

16. Jamarani, R., Erythropel, H. C., Nicell, J. A., Leask, R. L., \& Marić, M. (2018). How green is your plasticizer? Polymers, 10(8), 834. http://dx.doi.org/10.3390/polym 10080834 . PMid:30960759.

17. Karmalm, P., Hjertberg, T., Jansson, A., Dahl, R., \& Ankner, K. (2009). Network formation by epoxidised soybean oil in plastisol poly (vinyl chloride). Polymer Degradation \& Stability, 94(11), 1986-1990. http://dx.doi.org/10.1016/j. polymdegradstab.2009.07.029.

18. Mao, D., Chaudhary, B. I., Sun, B., Shen, C.-Y., Yuan, D., Dai, G.-C., Li, B., \& Cogen, J. M. (2015). Absorption and migration of bio-based epoxidized soybean oil and its mixtures with tri (2-ethylhexyl) trimellitate in poly (vinylchloride). Journal of Applied Polymer Science, 132(19), n/a. http://dx.doi.org/10.1002/ app.41966.

19. Chaudhary, B. I., Nguyen, B. D., Smith, P., Sunday, N., Luong, M., \& Zamanskiy, A. (2015). Bis (2-ethylhexyl) succinate in mixtures with epoxidized soybean oil as bio-based plasticizers for poly (vinylchloride). Polymer Engineering and Science, 55(3), 634-640. http://dx.doi.org/10.1002/pen.23934.

20. Coltro, L., Pitta, J. B., da Costa, P. A., Fávaro Perez, M. Â., de Araújo, V. A., \& Rodrigues, R. (2014). Migration of conventional and new plasticizers from PVC films into food simulants: a comparative study. Food Control, 44, 118-129. http://dx.doi.org/10.1016/j.foodcont.2014.03.058.

21. Choi, M. S., Rehman, S. U., Kim, H., Han, S. B., Lee, J., Hong, J., \& Yoo, H. H. (2018). Migration of epoxidized soybean oil from polyvinyl chloride/polyvinylidene chloride food packaging wraps into food simulants. Environmental Science and Pollution Research International, 25(5), 5033-5039. http:// dx.doi.org/10.1007/s11356-017-0951-9. PMid:29273993.

22. Jia, P., Xia, H., Tang, K., \& Zhou, Y. (2018). Plasticizers derived from biomass resources: a short review. Polymers, 10(12), 1303. http://dx.doi.org/10.3390/polym10121303. PMid:30961228.

23. Jia, P., Zhang, M., Hu, L., \& Zhou, Y. (2016). Green plasticizers derived from soybean oil for poly (vinyl chloride) as a renewable resource material. Korean Journal of Chemical Engineering, 33(3), 1080-1087. http://dx.doi.org/10.1007/s11814-015-02139.

24. Zheng, T., Wu, Z., Xie, Q., Fang, J., Hu, Y., Lu, M., Xia, F., Nie, Y., \& Ji, J. (2018). Structural modification of waste cooking oil methyl esters as cleaner plasticizer to substitute 
toxic dioctyl phthalate. Journal of Cleaner Production, 186, 1021-1030. http://dx.doi.org/10.1016/j.jclepro.2018.03.175.

25. Kandula, S., Stolp, L., Grass, M., Woldt, B., \& Kodali, D. (2017). Functionalization of soy fatty acid alkyl esters as bio plasticizers. Journal of Vinyl \& Additive Technology, 23(2), 93-105. http://dx.doi.org/10.1002/vnl.21486.

26. Moreira, D. R., Chaves, P. O. B., Ferreira, E. N., Arruda, T. B. M. G., Rodrigues, F. E. A., Câmara, J. F. No., Petzhold, C. L., Maier, M. E., \& Ricardo, N. M. P. S. (2020). Moringa polyesters as eco-friendly lubricants and its blends with naphthalenic lubricant. Industrial Crops and Products, 158, 112937. http://dx.doi.org/10.1016/j.indcrop.2020.112937.

27. American Society for Testing and Materials-ASTM. (2014). ASTM D1239-14: Standard Test Method for Resistance of Plastic Films to Extraction by Chemicals. West Conshohocken: ASTM.

28. Brasil. Ministério da Saúde. Agência Nacional de Vigilância Sanitária - ANVISA. Resolução $n^{\circ} 105$, de 19 de maio de 1999 (1999, 20 maio). Aprova os Regulamentos Técnicos: Disposições Gerais para Embalagens e Equipamentos Plásticos em contato com Alimentos. Diário Oficial da República Federativa do Brasil, Brasília.

29. Danov, S. M., Kazantsev, O. A., Esipovich,A. L., Belousov, A. S., Rogozhin,A. E., \& Kanakov, E. A. (2017). Recent advances in the field of selective epoxidation of vegetable oils and their derivatives: a review and perspective. Catalysis Science \& Technology, 7(17), 3659-3675. http://dx.doi.org/10.1039/C7CY00988G.

30. Köckritz, A., \& Martin, A. (2008). Oxidation of unsaturated fatty acid derivatives and vegetable oils. European Journal of Lipid Science and Technology, 110(9), 812-824. http://dx.doi. org/10.1002/ejlt.200800042.

31. Noor Armylisas, A. H., Siti Hazirah, M. F., Yeong, S. K., \& Hazimah, A. H. (2017). Modification of olefinic double bonds of unsaturated fatty acids and other vegetable oil derivatives via epoxidation: a review. Grasas y Aceites, 68(1), 174. http:// dx.doi.org/10.3989/gya.0684161.

32. Cheong, M., Hasan, Z. A. A., \& Idris, Z. (2019). Characterisation of epoxidised trimethylolpropane trioleate: NMR and thermogravimetric analysis. Journal of Oil Palm Research, 31(1), 146-158. http://dx.doi.org/10.21894/jopr.2018.0066.

33. Monteavaro, L. L., da Silva, E. O., Costa, A. P. O., Samios, D., Gerbase, A. E., \& Petzhold, C. L. (2005). Polyurethane networks from formiated soy polyols: synthesis and mechanical characterization. Journal of the American Oil Chemists 'Society, 82(5), 365-371. http://dx.doi.org/10.1007/s11746-005-1079-0.

34. Suzuki, A. H., Botelho, B. G., Oliveira, L. S., \& Franca, A. S. (2018). Sustainable synthesis of epoxidized waste cooking oil and its application as a plasticizer for polyvinyl chloride films. European Polymer Journal, 99, 142-149. http://dx.doi. org/10.1016/j.eurpolymj.2017.12.014.

35. Kim, J. R., \& Sharma, S. (2012). The development and comparison of bio-thermoset plastics from epoxidized plant oils. Industrial Crops and Products, 36(1), 485-499. http:// dx.doi.org/10.1016/j.indcrop.2011.10.036.

36. Borugadda, V. B., \& Goud, V. V. (2016). Physicochemical and rheological characterization of waste cooking oil epoxide and their blends. Waste and Biomass Valorization, 7(1), 23-30. http://dx.doi.org/10.1007/s12649-015-9434-8.

37. Chen, J., Liu, Z., Nie, X., \& Jiang, J. (2018). Synthesis and application of a novel environmental C26 diglycidyl ester plasticizer based on castor oil for poly (vinyl chloride). Journal of Materials Science, 53(12), 8909-8920. http://dx.doi. org/10.1007/s10853-018-2206-7.

38. Tong, H., \& Hai, J. (2019). Sustainable synthesis of bio-based hyperbranched ester and its application for preparing soft polyvinyl chloride materials. Polymer International, 68(3), 456-463. http://dx.doi.org/10.1002/pi.5730.

39. Bocqué, M., Voirin, C., Lapinte, V., Caillol, S., \& Robin, J. J. (2016). Petro-based and bio-based plasticizers: chemical structures to plasticizing properties. Journal of Polymer Science, Part A: Polymer Science, 54(1), 11-33. http://dx.doi. org/10.1002/pola.27917.

40. Ang, D. T. C., Khong, Y. K., \& Gan, S. N. (2016). Palm oilbased compound as environmentally friendly plasticizer for poly (vinyl chloride). Journal of Vinyl \& Additive Technology, 22(1), 80-87. http://dx.doi.org/10.1002/vnl.21434.

41. Tan, J., Liu, B., Fu, Q., Wang, L., Xin, J., \& Zhu, X. (2019). Role of the oxethyl unit in the structure of vegetable oilbased plasticizer for PVC: an efficient strategy to enhance compatibility and plasticization. Polymers, 11(5), 779. http:// dx.doi.org/10.3390/polym11050779. PMid:31052451.

42. Jia, P., Zhang, M., Hu, L., Feng, G., Bo, C., \& Zhou, Y. (2015). Synthesis and application of environmental castor oil based polyol ester plasticizers for poly (vinyl chloride). ACS Sustainable Chemistry \& Engineering, 3(9), 2187-2193. http://dx.doi.org/10.1021/acssuschemeng.5b00449.

43. Omrani, I., Ahmadi, A., Farhadian, A., Shendi, H. K., Babanejad, N., \& Nabid, M. R. (2016). Synthesis of a bio-based plasticizer from oleic acid and its evaluation in PVC formulations. Polymer Testing, 56, 237-244. http://dx.doi.org/10.1016/j. polymertesting.2016.10.027.

44. Ma, Y., Song, F., Hu, Y., Kong, Q., Liu, C., Rahman, M. A., Zhou, Y., \& Jia, P. (2020). Highly branched and nontoxic plasticizers based on natural cashew shell oil by a facile and sustainable way. Journal of Cleaner Production, 252, 119597. http://dx.doi.org/10.1016/j.jclepro.2019.119597.

45. Feng, G., Ma, Y., Zhang, M., Jia, P., Liu, C., \& Zhou, Y. (2019). Synthesis of bio-base plasticizer using waste cooking oil and its performance testing in soft poly (vinyl chloride) films. Journal of Bioresources and Bioprodcts, 4(2), 99-110. http:// dx.doi.org/10.21967/jbb.v4i2.214.

46. Schiller, M. (2015). PVC additives: performance, chemistry, developments, and sustainability. Munich: Carl Hanser Verlag. http://dx.doi.org/10.3139/9781569905449.

47. Mehta, B., Kathalewar, M., \& Sabnis, A. (2014). Diester based on castor oil fatty acid as plasticizer for poly (vinyl chloride). Journal of Applied Polymer Science, 131(11), 40354. http:// dx.doi.org/10.1002/app.40354.

48. Feng, G., Hu, L., Ma, Y., Jia, P., Hu, Y., Zhang, M., Liu, C., \& Zhou, Y. (2018). An efficient bio-based plasticizer for poly (vinyl chloride) from waste cooking oil and citric acid: synthesis and evaluation in PVC films. Journal of Cleaner Production, 189, 334-343. http://dx.doi.org/10.1016/j.jclepro.2018.04.085.

49. Yu, J., Sun, L., Ma, C., Qiao, Y., \& Yao, H. (2016). Thermal degradation of PVC: a review. Waste Management (New York, N.Y.), 48,300-314. http://dx.doi.org/10.1016/j.wasman.2015.11.041. PMid:26687228.

50. Marongiu, A., Faravelli, T., Bozzano, G., Dente, M., \& Ranzi, E. (2003). Thermal degradation of poly (vinyl chloride). Journal of Analytical and Applied Pyrolysis, 70(2), 519-553. http://dx.doi.org/10.1016/S0165-2370(03)00024-X.

51. Wang, Y., Nie, X., \& Li, X. (2016). Synthesis and characterization of novel pentaerythritol ester as PVC plasticizer. Journal of Applied Polymer Science, 133(47), 44227. http://dx.doi. org/10.1002/app.44227.

Received: Dec. 17, 2020

Revised: June 15, 2021

Accepted: Aug. 09, 2021 


\section{Supplementary Material}

Supplementary material accompanies this paper.

Figure S1: 1H-NMR spectrum of OTMP (CDCl3, $400 \mathrm{MHz})$.

Figure S2: 1H-NMR spectrum of EPO (CDCl3, $400 \mathrm{MHz})$.

Figure S3: GPC curves of plasticizers DOCH, OTMP, and EPO.

Figure S4: Second heating DSC curve of PVC resin (Norvic $\AA$, sp1000).

This material is available as part of the online article from https://www.scielo.br/j/po 